\title{
HMGB1: A Dangerous Player in Lupus Pathogenesis
}

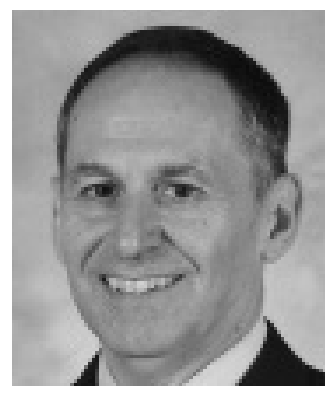

In an article in this issue of The Journal, Li, et al ${ }^{1}$ provide compelling evidence for a role of HMGB1 (high mobility group B1) in the pathogenesis of systemic lupus erythematosus (SLE) and highlight the potential of this molecule as both a biomarker and a target of new therapy. HMGB1 is a non-histone nuclear protein that has emerged as the prototypic alarmin ${ }^{2}$. While the terminology and classification of alarmins are in flux, alarmins can be considered as cellular components that stimulate the immune system when they leave their usual intracellular location during either cell activation or cell death. In other terminology, alarmins are danger signals, or DAMP (damage/death associated molecular patterns). Like PAMP (pathogen associated molecular patterns), DAMP can stimulate Toll-like receptors (TLR) to activate innate immunity ${ }^{3}$.

The importance of HMGB 1 in lupus is not unexpected in view of the mechanisms of its release from activated or dying cells and its surprisingly powerful immunological activity. These activities were initially discovered in seminal studies to identify immune mediators that could be targeted in sepsis more effectively than cytokines such as tumor necrosis factor- $\alpha(\text { TNF- } \alpha)^{4}$. While TNF blockade is successful in animal models, it did not work in human trials of this often fatal condition. The failure could reflect species differences or the transient production of TNF- $\alpha$ after PAMP stimulation. When infection became clinically obvious, TNF- $\alpha$ may have already left the scene, nullifying the action of a TNF blocker. Thus, the therapy of sepsis may require a target whose action still persists when the patient comes to medical attention ${ }^{5}$.

As shown in studies by Wang, et al, stimulation of macrophages by lipopolysaccharide (LPS) leads to the production of an immunologically active protein that importantly shows delayed production in in vitro and in vivo models ${ }^{4,6}$. The identity of this protein was a revelation, and revolutionized thinking on potential targets for new immunosuppressive agents. Thus, the active protein was found to be HMGB1, an abundant nuclear molecule that binds DNA and mediates chromosomal architecture and transcriptional regulation ${ }^{2}$. Subsequent studies showed that, to reach the extracellular space during activation, HMGB1 undergoes post-translational modification and then translocates from the nucleus to the cytoplasm to enter lysosomes for secretion by a nonconventional pathway ${ }^{7}$. This long journey may account for the time delay in its extracellular appearance.

In addition to its release during macrophage activation, HMGB 1 can exit cells during death ${ }^{8}$. As an architectural element for chromosomes, HMGB1 binds selectively to DNA and is only weakly adherent to chromatin ${ }^{9}$. Thus, when permeability barriers break down during cell death, HMGB1 easily traffics away from cells to become an alarmin, somewhat the way Clark Kent becomes Superman. Since HMGB1 is ubiquitous, it represents a potential danger signal for literally every cell type in the body, serving the same role in stimulating innate immunity as do cytokines. While initial studies suggested that HMGB1 release occurs with necrosis and not apoptosis, at least some cell types can release HMGB1 late in the apoptotic death process, a stage that can be called secondary necrosis. The HMGB1 released during apoptosis, however, may differ from that during necrosis because of its oxidative state ${ }^{10,11}$.

As these considerations indicate, lupus should provide the "perfect storm" for HMGB1 release. Thus, lupus is marked by intense immune activation as well as either increased apoptosis or a failure to clear away cells that have died. Further, given the conditions for the generation of extracellular HMGB1, these processes could work in a vicious cycle as products of dead cells drive immune activation and, in turn, cytokines and other mediators drive HMGB1 release. In this regard, while stimulation of macrophages with TLR ligands such as LPS (TLR4) and poly (I:C) (TLR3) leads to HMGB1 translocation, these molecules also induce macrophage apoptosis. It is thus pos-

See Expression of HMGB1 and modulating effects on downstream cytokines in SLE, page 766

Personal non-commercial use only. The Journal of Rheumatology Copyright (C) 2010. All rights reserved. 
sible that at least some of the HMGB1 released during macrophage activation results from apoptosis ${ }^{12}$.

$\mathrm{Li}$, et al demonstrate a dramatic increase in blood HMGB1 in SLE ${ }^{1}$. These findings are consistent with previous studies on the blood of patients as well as evidence of increased extracellular HMGB1 in patient skin ${ }^{13-16}$. These studies, however, do not specify the origin of HMGB1 with respect to release from activated, apoptotic, or necrotic cells, an issue that may be important in terms of the immune activity of HMGB1 (a consequence of post-translational modification and oxidation) as well as its association with other nuclear molecules. As shown in recent studies, HMGB1 may exist in the blood in SLE in the form of immune complexes with DNA and anti-DNA antibodies ${ }^{16}$. These complexes can stimulate plasmacytoid dendritic cells to produce type 1 interferon. Since HMGB1 can stimulate RAGE (receptor for advanced glycation endproducts) as well as TLR2, and TLR4 and DNA can stimulate TLR9, the signal delivered by these complexes is powerful because of simultaneous triggering of different pathways ${ }^{17}$.

The importance of HMGB1 in lupus may extend to autoantibody induction. Thus, in animal models, HMGB1, when bound to nucleosomes, can drive cytokine production and, in an immunization model with nucleosomes, stimulate induction of antibodies to histones and DNA in a TLR2-dependent manner ${ }^{18}$. Since free nucleosomes do not induce these autoantibody responses, these findings point to HMGB 1 as an autoadjuvant and emphasize the importance of the assembly of HMGB1 complexes with nucleosomes. Whether these complexes form intracellularly or extracellularly is not known, although this issue is relevant in developing strategies to separate these molecules and deprive nucleosomes of their dangerous partner.

While the physical-chemical form of HMGB1 in patient blood requires further investigation, nevertheless, in this study, the levels of HMGB1 showed impressive correlations with the SLE Disease Activity Index as well as inverse correlations with C4 and C3 levels. Further, levels of HMGB1 were notably higher in patients with vasculitis and myositis compared to patients without these manifestations. Since the patients with myositis had increased CPK levels, these findings could suggest that the HMGB1 in the blood originated from inflamed or damaged muscle cells. Indeed, other studies have demonstrated the extracellular expression of HMGB1 in patients with polymyositis and dermatomyositis ${ }^{19}$.

$\mathrm{Li}$, et al also showed that recombinant HMGB1 (rHMGB1) can stimulate in vitro cytokine production by peripheral blood cells from patients with lupus and normal controls. Differences, however, were observed in the magnitude and kinetics of the production of TNF- $\alpha$, and interleukin 6 (IL-6). Most notably, rHMGB1 did not induce TNF- $\alpha$ production by peripheral blood cells of patients with active lupus. This result is surprising in view of the elevation of TNF- $\alpha$ in some patients with lupus as well as the activity of HMGB1 in stimulating the production of cytokines and chemokines, including, as shown in this study, IL-6.

The basis of the impaired production of TNF- $\alpha$ by blood cells from patients with active lupus is not known, although these findings raise important questions about interpreting the immune activity of HMGB1. Thus, as shown in several studies, HMGB1 does not seem to act alone and, indeed, in the words of one author, "HMGB1 loves company"20-22. The recognition of this facet of HMGB1 activity came gradually and reflected findings that the in vitro activity of HMGB1 preparations varied depending on origin and purification and that very "clean" HMGB1 is actually devoid of activity. Addition of cytokines such as IL-1 or TNF- $\alpha$, or other molecules such as LPS or DNA, however, can restore HMGB1's immune properties, with HMGB1 acting synergistically with other mediators ${ }^{20-22}$.

The ability of HMGB1 to bind disparate partners may reflect its protein structure and the presence of amino acid sequences that can interact with biochemically disparate moieties. In the context of inflammation, this pattern of interaction may promote (or even underlie) the alarmin activity of HMGB1 by amplifying other danger signals. On the other hand, when these endogenous or exogenous signals diminish, HMGB1 may act alone, leading to either immunosuppression or angiogenesis to promote tissue reconstitution ${ }^{20}$. Thus, HMGB1 may have a double dose of dual functionality. Inside the cell, HMGB1 may bind DNA and determine chromosomal structure. Outside the cell, HMGB 1 may either be proinflammatory or antiinflammatory, depending on who else is in the neighborhood.

In the context of the current report, these findings suggest that the action of HMGB1 may reflect not only on the responsiveness of cells and their origin from patients with SLE with either or inactive disease; rather, this spectrum of cytokine production may reflect the content of other molecules in the culture. These molecules could include cytokines as well as DNA, which could be released from cells undergoing apoptosis; this apoptosis could result from prior immune cell activation in vivo or signaling abnormalities that make them prone to die in vitro. Elucidating this issue will likely require the use of other HMGB1 preparations and more defined purified cell populations. While there is now strong evidence that HMGB1 is an important agent in SLE, future studies will determine its interaction with other players in what is an increasingly large and diverse cast.

DAVID S. PISETSKY, MD, PhD,

Medical Research Service, Durham VA Hospital, Department of Medicine, Duke University Medical Center, Durham, North Carolina, USA

Supported by a VA Merit Review grant and grants from the Lupus Research Institute and the Alliance of Lupus Research. 
Address correspondence to Dr. D. Pisetsky, Department of Medicine and Immunology, Medical Research Service, Durham VA Hospital, $151 G$ Durham VAMC, 508 Fulton Street, Durham, NC 27705.

E-mail:dpiset001@mc.duke.edu

\section{REFERENCES}

1. Li J, Xie H, Wen T, Liu H, Zhu W, Chen X. Expression of high mobility group box chromosomal protein 1 (HMGB1) and the modulating effects on downstream cytokines in systemic lupus erythematosous. J Rheumatol 2010;37:766-75.

2. Pisetsky DS, Erlandsson-Harris H, Andersson U. High-mobility group box protein 1 (HMGB1): an alarmin mediating the pathogenesis of rheumatic disease. Arthritis Res Ther 2008;10:209.

3. Bianchi ME. DAMPs PAMPs and alarmins: all we need to know about danger. J Leukoc Biol 2007;81:1-5.

4. Wang H, Bloom O, Zhang M, Vishnubhakat JM, Ombrellino M, Che J, et al. HMG-1 as a late mediator of endotoxin lethality in mice. Science 1999;285:248-51.

5. Ulloa L, Tracey KJ. The 'cytokine profile': a code for sepsis. Trends Mol Med 2005;11:56-63.

6. Andersson U, Wang H, Palmblad K, Aveberger A, Bloom O, Erlandsson-Harris $\mathrm{H}$, et al. High mobility group 1 protein (HMG-1) stimulates proinflammatory cytokine synthesis in human monocytes. J Exp Med 2000;192:565-70.

7. Bonaldi T, Talamo F, Scaffidi P, Ferrera D, Porto A, Bachi A, et al. Monocytic cells hyperacetylate chromatin protein HMGB1 to redirect it towards secretion. EMBO J 2003;22:5551-60.

8. Rovere-Querini P, Capobianco A, Scaffidi P, Valentinis B, Catalanotti F, Giazzon M, et al. HMGB1 is an endogenous immune adjuvant released by necrotic cells. EMBO J 2004;5:825-30.

9. Falciola L, Spada F, Calogero S, Langst G, Voit R, Grummit I, et al. High mobility group 1 protein is not stably associated with the chromosomes of somatic cells. J Cell Biol 1997;137:19-26.

10. Bell CW, Jiang W, Reich CF, Pisetsky DS. The extracellular release of HMGB1 during apoptotic cell death. Am J Physiol 2006; 291:18-25.

11. Kazama H, Ricci JE, Herdon JM, Hoppe G, Green DR, Ferguson TA. Induction of immunological tolerance by apoptotic cells requires caspase-dependent oxidation of high-mobility group box-1 protein. Immunity 2008;29:1-2.

12. Jiang W, Bell CW, Pisetsky DS. The relationship between apoptosis and high-mobility group protein 1 release from murine macrophages stimulated with lipopolysaccharide or polyinosinic-polycytidylic acid. J Immunol 2007;178:6495-503.
13. Jiang W, Pisetsky DS. Expression of high mobility group protein 1 in the sera of patients and mice with systemic lupus erythematosus. Ann Rheum Dis 2008;67:727-8.

14. Urbonaviciute V, Furnrohr BG, Weber C, Haslbeck M, Wilhelm S, Herrmann M, et al. Factors masking HMGB1 in human serum and plasma. J Leukoc Biol 2007;81:67-74.

15. Popovic K, Elk M, Espinosa A, Padyukov L, Erlandsson-Harris H, Wahren-Herlenius M, et al. Increased expression of the novel proinflammatory cytokine high mobility group box chromosomal protein 1 in skin lesions of patients with lupus erythematosus. Arthritis Rheum 2005;52:3639-45.

16. Tian J, Avalos AM, Mao SY, Chen B, Senthil K, Wu H, et al. Toll-like receptor 9-dependent activation by DNA-containing immune complexes is mediated by HMGB1 and RAGE. Nature Immunol 2007;8:487-96.

17. Park JS, Gamboni-Robertson F, He Q, Svetkauskaite D, Kim JY, Strassheim D, et al. High mobility group box 1 protein interacts with multiple toll-like receptors. Am J Physiol Cell Physiol 2006;290:c917-c924.

18. Urbonaviciute V, Furnrohr BG, Meister S, Munoz L, Heyder P, de Marchis F, et al. Induction of inflammatory and immune responses by HMGB1 - nucleosome complexes: implications for the pathogenesis of SLE. J Exp Med 2009;205:3007-18.

19. Ulfgren AK, Grundtman C, Borg K, Alexanderson H, Andersson U, Harris HE, et al. Down-regulation of the aberrant expression of the inflammation mediator high mobility group box chromosomal protein 1 in muscle tissue of patients with polymyositis and dermatomyositis treated with corticosteroids. Arthritis Rheum 2004;50:1586-94.

20. Bianci ME. HMGB1 loves company. J Leukoc Biol 2009;86:573-76.

21. Sha Y, Zmijewski J, Xu Z, Abraham E. HMGB1 develops enhanced proinflammatory activity by binding to cytokines. J Immunol 2008;180:2531-7.

22. Hreggvidsdottir HS, Ostberg T, Wahamaa H, Schierbeck H, Aveberger AC, Klevenvall L, et al. The alarmin HMGB1 acts in synergy with endogenous and exogenous danger signals to promote inflammation. J Leukoc Biol 2009;86:655-62.

J Rheumatol 2010;37:689-91; doi:10.3899/jrheum.091459 